\title{
Familial amyloidotic polineuropathy and systemic lupus
}

\author{
AC Ferreira, F Carvalho and F Nolasco \\ Department of Nephrology, Centro Hospitalar de Lisboa Central, Hospital de Curry Cabral, Lisbon, Portugal
}

\begin{abstract}
Familial amyloidotic polineuropathy is a genetic disorder, leading to systemic amyloid deposits, manifested as sensory-motor and autonomic neuropathy. In the Portuguese classical form, the disease is evident at a young age, and causes death if no specific treatment is received. Variability in penetrance, age of onset and clinical course has been published; environmental and genetic factors are believed to contribute to this variability.

The authors report a case of a 51-year-old white female, with a medical history of acquired angioedema, late-onset familial amyloidotic polineuropathy and systemic lupus erythemathosus. The authors consider that these associated diseases could modulate their expression. Lupus (2012) 21, 1455-1458.
\end{abstract}

Key words: Systemic lupus erythematosus; renal lupus; familial amyloidotic polineuropathy; modulation

\section{Background}

Portuguese familial amyloidotic polyneuropathy (FAP) is a genetic autosomal dominant disorder, caused by an amino acid substitution of methionine for valine at position $30(\mathrm{~V} 30 \mathrm{M})$ of the transthyretin (TTR) molecule, leading to diffusely distributed amyloid deposits of fibril protein in the peripheral nervous system. ${ }^{1,2}$ Nevertheless, this amino-acid substitution alone does not explain penetrance, age of onset and clinical course of the disease. In Portuguese variants, the incidence of penetrance is high $(80 \%)$, and the disease is evident before the age of $40 .^{2}$ The disease typically causes a nerve length-dependent sensorimotor polyneuropathy, but potentially unmyelinated and small myelinated fibres can also be involved. The symptoms start in the lower extremities, with spontaneous pains, numbness and loss of temperature sensations that extend above the ankle level. Motor deficit also occurs, with loss of balance and stepping gait. ${ }^{3}$ The disease progresses with a multisystemic involvement: autonomic dysfunction causing orthostatic hypotension, cardiac arrhythmias, gastrointestinal dysmotility, erectile dysfunction and sphincter disturbances. ${ }^{1,2}$ Renal involvement is common.

Correspondence to: Ana Carina Ferreira, Rua da Beneficência $n^{\circ} 8$, 1069-639 Lisboa.

Email: karinadacostafer@hotmail.com

Received 7 March 2012; accepted 25 July 2012
All patients have been found to have amyloid deposits in the kidney, but not all had nephropathy. ${ }^{2}$ FAP nephropathy has special epidemiological features; only one-third of patients develop chronic kidney disease (CKD) and 10 per cent progress to CKD stage $5 \mathrm{~d}^{2}$

Without treatment, the patients die after 8-10 years, following the development of muscular atrophy, severe autonomic neuropathy, cachexia and malnutrition. Because more than 90 per cent of the mutant protein is produced by the liver, orthotopic liver transplantation has been proposed to treat this disease.

Subsets of families with late onset and aged asymptomatic patients have been identified. Environmental and genetic factors are believed to contribute to this variability.

\section{Case report}

A 51-year-old white female with V30M TTR genetic diagnosis in January 2009, was referred to our nephrology appointment by the Hepatic Transplant Unit, to be evaluated for liver and kidney transplant requirement.

The patient has a familial history of FAP and CKD. Her mother died with malnutrition, inflammation and atherosclerosis syndrome, on dialysis, without being diagnosed for FAP. Her brother died with muscular atrophy and malnutrition, and had 


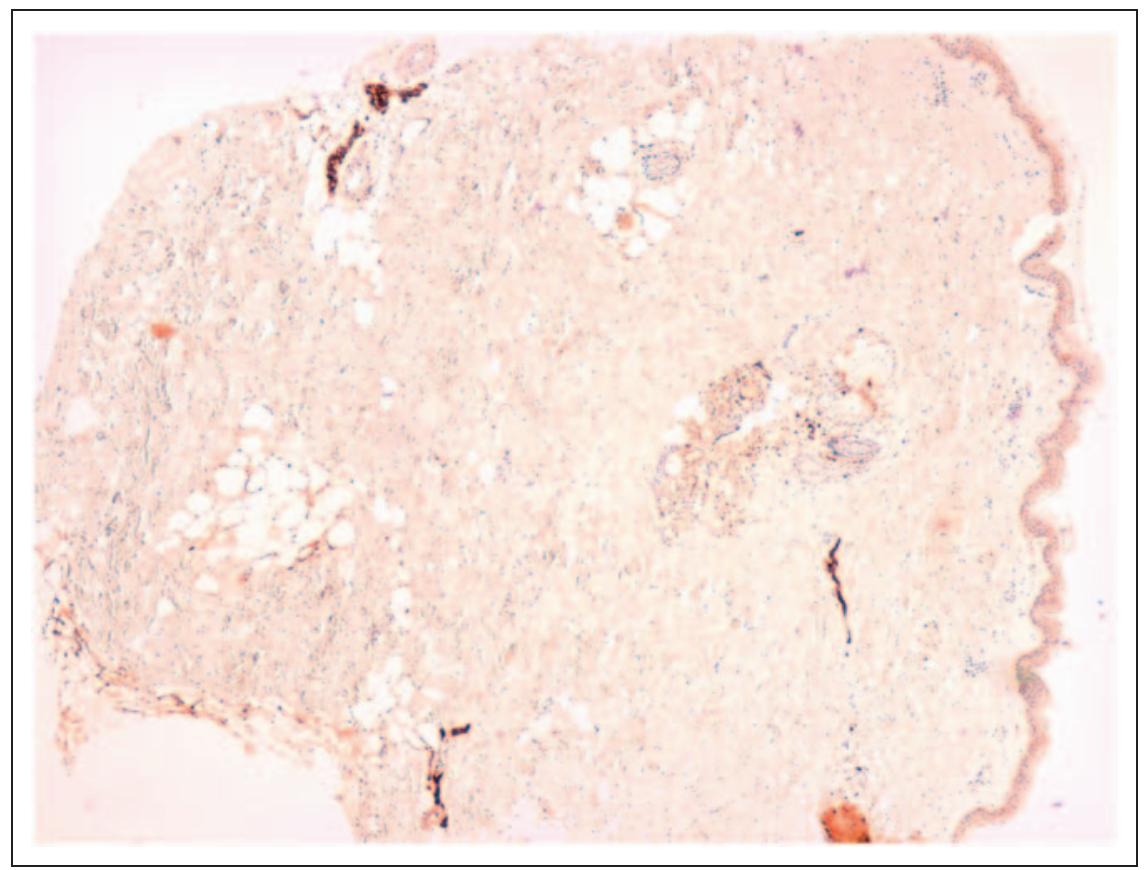

Figure 1 Skin section with normal dermal nerves (anti-PS100 antibody, peroxidase immunostaining in paraffin section $\times 40$ ).

been diagnosed with FAP. Her twin sister has CKD of an unknown cause, and received a kidney transplant; she does not have FAP symptoms and refuses to receive genetic tests.

The patient has no manifestations of FAP other than first-degree atrioventricular block. She has a medical history of acquired angioedema since her forties, without any current medication.

The laboratory data revealed $\mathrm{Hg} 13.1 \mathrm{~g} / \mathrm{dl}, \mathrm{WBC}$ 6200 , thrombocytes $99,000 / \mathrm{mm}^{3}$, serum creatinine (Scr) $1.3 \mathrm{mg} / \mathrm{dl}$, sodium $137 \mathrm{mEq} / 1$, potassium $5.1 \mathrm{mEq} / 1$, calcium $9.4 \mathrm{mg} / \mathrm{dl}$, phosphorus $3.9 \mathrm{mg} /$ $\mathrm{dl}$, albumin $4.2 \mathrm{~g} / \mathrm{dl}$ and uric acid $6.4 \mathrm{mg} / \mathrm{dl}$. Paraprotein was negative in plasma and urine. Urine had $10 \mathrm{mg} / \mathrm{dl}$ protein and haemoglobin $(++)$ on dipstick testing, sediment revealed many haematocytes/field and culture was negative; 24 hours' collection showed $1.3 \mathrm{~g}$ of proteinuria. Complement study revealed normal $\mathrm{C} 1$-inhibitor levels (38.2 mg/dl, normal range 21-39) and normal C1-inhibitor function $(134 \%$, normal $>68 \%)$, normal C1q levels $(12.8 \mathrm{mg} / \mathrm{dl}$, normal range 11.8-24.4), low C3 (61 mg/dl, normal range $75-140)$ and borderline $\mathrm{C} 4(11 \mathrm{mg} /$ $\mathrm{dl}$, normal range 10-34). The patient tested negative for cryoglobulinaemia.

ANAs were positive $(1 / 320)$; dsDNA was positive $(149.7 \mathrm{U} / \mathrm{ml}$, normal $<100)$ and anti-nucleosomes were positive $(71.3 \mathrm{U} / \mathrm{ml}$, normal $<20)$. Antiphospholipid antibodies were positive, including IgG anticardiolipin (19.8 UGPL, normal $\leq 12)$ and IgG anti- $\beta 2$ glycoprotein-I (12.3 USGU, normal $\leq 12$ ).

Ultrasound showed normal-sized and differentiated kidneys, without post-mictional residue. Creatinine clearance by DTPA was $57.6 \mathrm{ml} / \mathrm{min}$.

Despite thrombocytopenia, a skin and a renal biopsy were performed. In the skin biopsy, lupus band test was positive and vascular amyloid deposits were present. Other morphological features of the skin biopsy were normal: there were no other lesions like vasculitis, and nerve distribution and appearance were normal, without atrophy, when using Protein S100 marker (Figure 1). The kidney biopsy had seven glomeruli, three with segmental and difuse mesangial proliferation (Figure 2a). The interstitium and tubules were normal, and there were sparse amyloid deposits in the medulla. The arteries had amyloid deposits in the media. Immunostaining was positive for $\mathrm{C} 3(+), \mathrm{C} 4(+)$, Clq (++), IgG (+) and IgM (+). Anti-TTR was positive (Figure 2b). Diagnosis of systemic lupus erythematosus (SLE) with lupus nephritis Class II and renal TTR amyloidosis were made.

\section{Discussion}

This is a case where three rare diseases are linked, and this association could alter their clinical manifestations. 


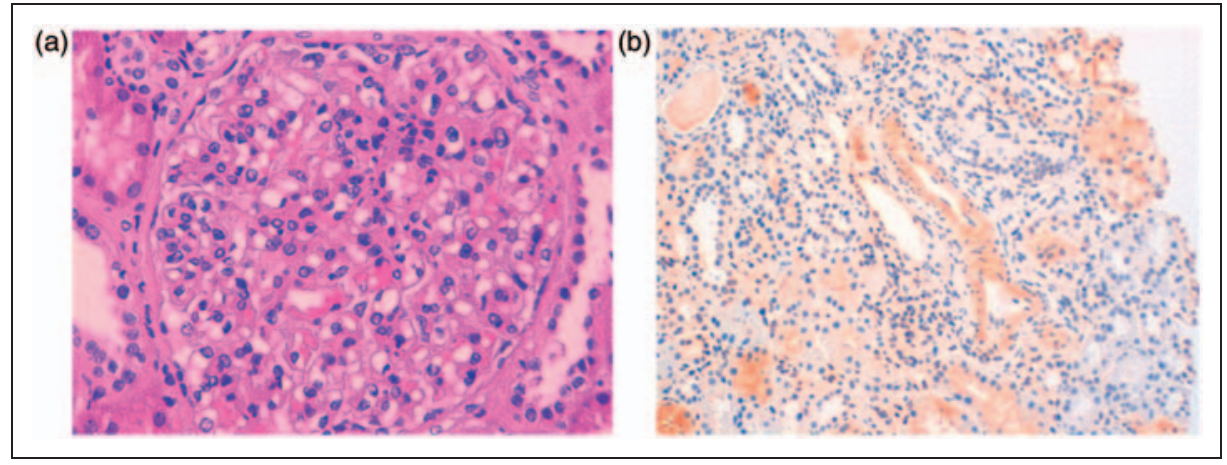

Figure 2 (a) Segmental and difuse mesangial proliferation $(\mathrm{HE} \times 400)$. (b) Amyloid deposits in the media, with anti-TTR positive $($ TTR $\times 200)$.

Portuguese variant FAP usually manifests with neurological abnormalities at a young age. There are reported Portuguese cases with late-onset or no manifestations despite genetic disease, and it has been suggested that environmental factors contribute to this phenotype variability.

Recently, it has been shown that in V30M TTR Portuguese type, differences in penetrance are dependent of the transmitting parent, being higher in the case of maternal transmission. ${ }^{4}$ In addition, another study demonstrated that mitochondrial polymorphism effect was sufficient to explain higher penetrance in the case of maternal inheritance of the disease. ${ }^{5}$

Variability in age of onset has also been studied. Nylander showed that genetic variants of complement factors $\mathrm{C} 3$ and isotype $\mathrm{C} 4 \mathrm{~A}$ may interact with the mutant TTR, modifying the expression and age of onset of FAP. ${ }^{6}$ More recently, Clq and its single nucleotide polymorphism in $\mathrm{ClqA}$ and $\mathrm{ClqC}$, were implicated in different age of onset in Cypriot patients. ${ }^{7}$

In addition to FAP, this patient suffers from SLE. The involvement of complement in the aetiopathogenesis of SLE has been reported. Activation of the complement system plays an important role in tissue damage, as a consequence of immune complex deposition, formed during the course of the disease. A hereditary deficiency of the early components of the classical pathway has been associated with development of SLE: homozygous deficiency of C4A and heterozygous deficiency of C4A and/or $\mathrm{C} 4 \mathrm{~B}$ is relatively frequent and reported in patients with SLE; homozygous C1q deficiency is also associated with SLE, usually with severe manifestations; homozygous C3 deficiency seldom develops SLE. ${ }^{8}$ Nonetheless, SLE can also be an acquired disease. The classical example is angioedema: C1-inhibitor deficiency causes unregulated activation of the kininogen and complement systems, with consequent reduced serum levels of C2 and C4, following SLE development. ${ }^{8}$ Of note this patient has a medical history of acquired angioedema.

In addition to FAP, neurological involvement is also reported in SLE. Patients present with a myriad of signs, involving the brain, spinal cord or peripheral nervous system. Although pathogenesis is unknown, neurological involvement seems to be caused by vascular disease affecting small vessels, namely perivascular inflammation or noninflammatory hyalinization. True vasculitis as the cause for neurological dysfunction is very rare. Vasculitis is a blood vessel inflammation accompanied by reactive lesion of the affected vessels. In SLE, all sizes of vessels may be affected, and vasculitis can be cutaneous or visceral, with the former making up the majority of cases. Cutaneous vessel involvement is usually present as punctuate lesions, purpuric plaques, cutaneous necrosis, ulcerations or nodules, and the definitive diagnosis is made by biopsy. In this patient no skin lesions were observed.

Peripheral nervous system manifestations occur in 2-21 per cent of neuropsychiatric patients, and antineuronal antibodies have been implicated. Despite these numbers, there are multiple causes of peripheral nervous system involvement, which must be considered, evaluated and ruled out before attributing these symptoms to SLE.

As with FAP, the most common presentation is a distal sensorimotor neuropathy. ${ }^{9}$ Patients with distal, symmetric, peripheral polyneuropathy can present with a mild to severe sensory or sensorimotor fibre involvement, as numbness, dysaesthesias or hypaesthesias. Nevertheless, recent studies of skin biopsies demonstrated involvement of small, non-myelinated afferent nerve fibres and skin denervation. ${ }^{10}$ This last issue was also reported in FAP due to Ala97Ser mutation of TTR, 
indicating that small-fibre sensory neuropathy is one of the most prevalent components of these patients with FAP, compared with other types of neuropathy. ${ }^{11}$ To our knowledge, no reported cases of skin denervation were observed in Val30Met mutations.

The skin biopsy of our patient was performed in normal skin (without macroscopic lesions), in the deltoid region of the left arm. There were no signs of vasculitis, and no signs of intraepidermal nerve fibre reduction or morphological alteration. It is important to note that our patient did not have neurological manifestations of FAP (or SLE), other than first-degree atrioventricular block. Autonomic disorders can also appear in SLE. ${ }^{9}$

We emphasise that this patient has a monozygotic twin sister with a discordant clinical phenotype. It is likely that her sister also has late-onset FAP. Although genetic influences are crucial to SLE, concordance rate of the disease in monozygotic twins varies between 24 and 58 per cent, indicating that non-germline factors are required for the development of the disease. Hence, we may presume that she does not have SLE or that her past history of dialysis could decrease clinical and serological activity of the disease, a phenomenon known as SLE burn out.

In conclusion it seems that in this particular case, complement deficiency was crucial for the development of SLE and acquired angioedema, and probably was the cause for late onset of FAP disease. In addition, we can also suppose that FAP and SLE could interact and change clinical course of both, as was demonstrated in patients with AA amyloidosis and SLE. As a result, TTR protein could be deposited in lupus tissues without evidence of clinical amyloid, and could be protective against lupus.

\section{Acknowlegement}

The authors thank Dr Luísa Lobato PhD for the support and Dr Ana Afonso for revising the slides of the skin biopsy.

\section{Funding}

This research received no specific grant from any funding agency in the public, commercial, or notfor-profit sectors.

\section{Conflict of interest}

The authors have no conflicts of interest to declare.

\section{References}

1 Andrade C. A peculiar form of peripheral neuropathy: familiar atypical generalized amyloidosis with special involvement of the peripheral nerves. Brain 1952; 75: 408-427.

2 Lobato L, Beirão I, Guimarães SM, et al. Familial amyloidotic polyneuropathy type I (Portuguese): distribution and characterization of renal amyloid deposits. Am J Kidney Dis 1998; 31: 940-946.

3 Planté-Bordeneuve V, Said G. Familial amyloid polyneuropathy. Lancet Neurol 2011; 10: 1086-1097.

4 Bonaïti B, Alarcon F, Bonaïti-Pellié C, et al. Parent of origin effect in transthyretin related amyloid polyneuropathy. Amyloid 2009; 16 : $149-150$.

5 Bonaïti B, Olsson M, Hellman U, et al. TTR familial amyloid polyneuropathy: does a mitochondrial polymorphism entirely explain the parent-of-origin difference in penetrance? Eur J Hum Genet 2010; 18: 948-952.

6 Nylander PO, Beckman L, Holmgren G, et al. Association of C3 and $\mathrm{C} 4 \mathrm{~A}$ complement types with familial amyloidotic polyneuropathy. Hum Hered 1990; 40: 272-277.

7 Dardiotis E, Koutsou P, Zamba-Papanicolaou E, et al. Complement C1Q polymorphisms modulate onset in familial amyloidotic polyneuropathy TTR Val30Met. J Neurol Sci 2009; 284: $158-162$.

8 Liu CC, Ahearn J. Complement and systemic lupus erythematosus. Dubois' lupus erythematosus, 7th edn. Philadelphia, PA: Lippincott Williams \& Wikins; 2007. p. 214-229.

9 McCombe PA, McLeod GP, Pllard JD, et al. Peripheral sensorimotor and autonomic neuropathy associated with systemic lupus erythematosus. Clinical, pathological, and immunological features. Brain 1987; 110: 533-549.

10 Goransson LG, Brun JG, Harboe E, et al. Intraepidermal nerve fiber densities in chronic inflammatory autoimmune diseases. Arch Neurol 2006; 63: 1410-1413.

11 Yang NC-C, Lee MJ, Chao C-C, et al. Clinical presentation and skin denervation in amyloid neuropathy due to transthyretin Ala97Ser. Neurology 2010; 75: 532-538. 
Copyright of Lupus is the property of Sage Publications, Ltd. and its content may not be copied or emailed to multiple sites or posted to a listserv without the copyright holder's express written permission. However, users may print, download, or email articles for individual use. 